Original article

\title{
Evaluation of the self-concept of mothers with educable mentally retarded (EMR) children
}

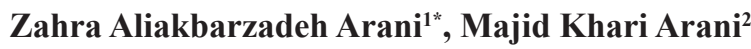

(Received: 6 Oct 2015; Accepted: 22 Jan 2016)

\begin{abstract}
Background and Purpose: Birth of a mentally retarded child is a significant challenge in every family and is associated with the possibility of parental stress and depression. This study aimed to evaluate the self-concept of mothers with educable mentally retarded (EMR) children.
\end{abstract}

Methods: This cross-sectional study was conducted on 40 mothers with EMR children in the only special primary school for these children in Aran \& Bidgol city in Isfahan, Iran. Data were collected using self-concept questionnaires. Data analysis was performed using descriptive statistics and Fisher's exact test in SPSS V.13.

Results: In this study, total score of the self-concept of mothers was $29.95 \pm 7.60$, which was relatively desirable. In addition, a significant correlation was observed between the age of children $(\mathrm{P}=0.02)$ and family income status $(\mathrm{P}=0.01)$ with the scores of maternal selfconcept.

Conclusion: According to the results of this study, higher family income and increased age of EMR children are associated with higher self-concept of mothers. It is recommended that future studies be performed on larger sample sizes in this regard.

Keywords: Children, Mental retardation, Self-concept

\section{Introduction}

Birth of a mentally retarded child is a major challenge in every family, which might be followed by problems such as parental stress and depression. Moreover, it could expose other family members to the risk of mental disorders (1). Typically, the mother is under the maximum pressure in a family (2). In one study, Koohsali et al. stated that mothers with mentally retarded children tolerate high levels of stress and depressive symptoms, as well as family breakdown (3).

On the other hand, findings of Kermanshahi et al. indicated that mothers with mentally retarded children resort to spirituality as the only support to cope with the unique condition of their child (4). In the United States, people with intelligence of two or more standard deviations below the mean account for $3 \%$ of the total population (5). According to the statistics provided by the Iranian

\footnotetext{
${ }_{1,{ }^{*}}$ Corresponding author: Department of Operating Room, Faculty of Paramedical, Qom University of Medical Sciences, Qom, Iran. Email: Zaliakbarzade@muq.ac.ir

${ }^{2} \mathrm{PhD}$ Student in Education and Training, Shahed University, Tehran, Iran
} 
State Welfare Organization in 2006, our country has about 2,008,000 individuals with general disabilities, 28,795 of whom suffer from mental disorders (6). Moreover, a significant number of families in Iran are faced with the complications associated with having mentally disabled children, and these problems are extensively neglected in these families.

The view of mothers as "little more than architects of the perfect child" has important implications for the self-concept of mothers (7). Self-concept is defined as the combination of one's perceptions and values with regard to him/herself, which is constructed through social interactions. Recent theories on the development of self-concept tend to focus on an individual's view of self in comparison to others (8).

In this regard, Tomey \& Alligood (2006) believe that self-concept mostly entails the psychological aspects of human life and is defined by the individual and other important people in their life $(9,10)$. For instance, symbolic interactionism is a sociological perspective, which argues that self-concept is established through social interactions of an individual with others (8).

Self-concept largely affects the social adjustment of mothers (11), as well as the self-esteem of children. Parents are the main role models for children, and since children spend most of their time with their mothers, maternal self-concept is considered as a significant predictor for the self-concept of children in future (12). Several studies have evaluated the impact of childbirth with congenital anomalies on the families proposing controversial results. When parents face with the challenges of a mentally retarded child, they attempt to find the necessary guidance in order to cope with this phenomenon (13).

Considering the high prevalence of mental health and communication problems in the parents of children with mental disabilities, it is essential to conduct extensive research on the factors that could increase the tolerance of the parents in coping with mentally retarded children, especially mothers. This could modify the knowledge and attitude of parents towards the special condition of their children to maintain their self-concept and mental health.

To date, no studies have been performed to assess the effects of childbirth with congenital anomalies on the self-concept of parents. This study aimed to evaluate the self-concept of mothers with educable mentally retarded (EMR) children.

\section{Materials and Methods}

This cross-sectional study was conducted on 40 mothers with EMR children in the only special primary school for these children in Aran \& Bidgol city in Isfahan, Iran during 2010-2011. Participants were selected via random sampling based on the Poisson model. Inclusion criteria were having at least one EMR child in primary school (age range: 6-17 years), ability to read and write, and absence of mental disorders. Unwillingness of the mothers to participate in the research was the only exclusion criterion. Accordingly, five mothers who refused to participate were excluded from the study population.

To collect the required data, we used a two-part questionnaire. The first section of the questionnaire consisted of maternal demographic data, such as age, education level, employment status, number of children, family income, and familial relations of parents. Moreover, demographic data of the children, including age, gender, birth rank, severity of mental disability, and possible causes of mental disability (based on the information in school files), were recorded.

As developed by the researcher through the review of literature, the second section of the questionnaire focused on maternal self-concept $(3,14)$. This scale was designed based on the Roy's adaptation model, which was first developed by a nursing theorist. Roy's adaptation model is divided into four main categories of physiological, self-concept, dependence/independence, and role-playing. The self-concept questionnaire consisted of 18 items that were scored based on a fourpoint Likert scale (never=zero, always $=3$ ), within a score range of $0-54$, as follows: undesirable (scores $0-18$ ), relatively desirable (scores 19-36), and desirable self-concept (scores 37-54).

Content validity of the self-concept questionnaire was examined by a panel of experts in Tehran University of Medical Sciences, and the reliability was determined to be 0.84 using the test-retest method in 10 mothers at a two-week interval.

All mothers were invited to the study via phone calls, 
and the questionnaires were completed using selfreports. Objectives of the study were explained to the mothers, and written informed consent was obtained prior to participation. Moreover, all participants were granted terms of confidentiality with regard to their personal information. Study protocol was approved by the Ethics Committee of the Research Deputy of Tehran University of Medical Sciences (Grant No. 25.250.D.2010). Furthermore, the researchers attempted to preserve the rights of the participants in accordance with the Declaration of Helsinki.

Data analysis was performed in SPSS V.13 using descriptive statistics to describe the demographic and baseline characteristics of the participants (i.e., mean, standard deviation, number, and percentage). To determine the correlations between self-concept and each demographic variable, the Fisher's exact test was used, and $\mathrm{P}$ value of less than 0.05 was considered significant.

\section{Results}

In total, 40 mothers with mean age of $28.38 \pm 7.95$ years were enrolled in this study. The majority of the participants were housewives $(90 \%)$ and had primary education (77.5\%). In addition, the majority of the

Table 1. Frequency and percentage of self-concept based on different maternal variables

\begin{tabular}{|c|c|c|c|c|}
\hline & $\begin{array}{c}\text { Desirable } \\
\text { N (\%) }\end{array}$ & $\begin{array}{c}\text { Relatively } \\
\text { Desirable } \\
\text { N (\%) }\end{array}$ & $\begin{array}{c}\text { Undesirable } \\
\text { N (\%) }\end{array}$ & $\begin{array}{c}\text { Fisher's } \\
\text { Exact Test/ } \\
\text { P-value }\end{array}$ \\
\hline \multicolumn{5}{|l|}{ Age (years) } \\
\hline $25-35$ & $2(5)$ & $15(37.5)$ & $1(2.5)$ & \\
\hline $35-45$ & $3(7.5)$ & $11(27.5)$ & $0(0)$ & 5.26 \\
\hline $45 \geq$ & $2(5)$ & $4(10)$ & $2(5)$ & 0.21 \\
\hline \multicolumn{5}{|l|}{ Number of Children } \\
\hline $1-3$ & $3(7.5)$ & $22(55)$ & $2(5)$ & 2.55 \\
\hline$\geq 3$ & $4(10)$ & $8(20)$ & $1(2.5)$ & 0.31 \\
\hline \multicolumn{5}{|l|}{ Education Level } \\
\hline Elementary & $6(15)$ & $21(52.5)$ & $3(7.5)$ & 1.8 \\
\hline High School & $1(2.5)$ & $9(22.5)$ & $0(0)$ & 0.4 \\
\hline \multicolumn{5}{|l|}{ Diploma and Above } \\
\hline \multicolumn{5}{|l|}{ Employment Status } \\
\hline Employed & $0(0)$ & $3(7.5)$ & $0(0)$ & 0.68 \\
\hline Unemployed & $7(17.5)$ & $27(67.5)$ & $3(7.5)$ & 1 \\
\hline \multicolumn{5}{|l|}{ Family Income } \\
\hline \multicolumn{5}{|l|}{ Status } \\
\hline Adequate & $3(7.5)$ & $3(7.5)$ & $0(0)$ & \\
\hline Relatively Adequate & $4(10)$ & $18(45)$ & $0(0)$ & 10.65 \\
\hline Inadequate & $0(0)$ & $9(22.5)$ & $3(7.5)$ & 0.01 \\
\hline \multicolumn{5}{|l|}{$\begin{array}{l}\text { Family History of } \\
\text { Mental Retardation }\end{array}$} \\
\hline None & $7(17.5)$ & $20(50)$ & $3(7.5)$ & \\
\hline Maternal History & $0(0)$ & $6(15)$ & $0(0)$ & 3.59 \\
\hline Paternal History & $0(0)$ & $4(10)$ & $0(0)$ & 0.13 \\
\hline
\end{tabular}

mothers $(67.5 \%)$ had two children. In $37.5 \%$ of the cases, mental retardation was reported in the first child, and in 52.5\%, EMR children were male. In this study, mean score of maternal self-concept was $29.95 \pm 7.60$ years, which was relatively desirable.

The results of this study were indicative of significant correlations between maternal selfconcept, age of the child ( $\mathrm{P}=0.02)$, and family income status $(\mathrm{P}=0.01)$. However, no significant correlations were observed between the self-concept of mothers and factors such as maternal age, education level, employment status, number of children, gender of the child, severity of mental disorders, birth rank, cause of disorders, and family history of retardation (Tables $1 \& 2$ ).

\section{Discussion}

According to the results of the present study, mean score of the self-concept of mothers with EMR children was relatively desirable. Mothers may blame themselves for the birth of a child with disabilities, and this could adversely affect their self-concept. On the other hand, some of the mothers with EMR children adopt spirituality to cope with their unique condition.

In one study, Moore (2005) claimed that the time

Table 2. Frequency and percentage of maternal self-concept based on different variables of EMR* children

\begin{tabular}{|c|c|c|c|c|}
\hline & $\begin{array}{c}\text { Desirable } \\
\text { N (\%) }\end{array}$ & $\begin{array}{c}\text { Relatively } \\
\text { Desirable } \\
\text { N (\%) }\end{array}$ & $\begin{array}{c}\text { Undesirable } \\
\text { N (\%) }\end{array}$ & $\begin{array}{c}\text { Fisher's } \\
\text { Exact Test/ } \\
\text { P-value }\end{array}$ \\
\hline \multicolumn{5}{|l|}{ Age (years) } \\
\hline $5-10$ & $0(0)$ & $17(42.5)$ & $1(2.5)$ & \multirow{3}{*}{$\begin{array}{l}9.07 \\
0.02\end{array}$} \\
\hline $10-15$ & $5(12.5)$ & $9(22.5)$ & $2(5)$ & \\
\hline $15-20$ & $2(5)$ & $4(10)$ & $0(0)$ & \\
\hline Birth Rank & & & & \\
\hline First Child & $\begin{array}{c}0(0) \\
7(175)\end{array}$ & $13(32.5)$ & $\begin{array}{l}2(3) \\
1(05)\end{array}$ & 0.11 \\
\hline $\begin{array}{l}\text { Second Child and } \\
\text { Above }\end{array}$ & $7(17.5)$ & $17(42.5)$ & & \\
\hline \multicolumn{5}{|l|}{ Gender } \\
\hline Female & $3(7.5)$ & $5(12.5)$ & $1(2.5)$ & 0.51 \\
\hline Male & $4(10)$ & $15(37.5)$ & $2(5)$ & 1 \\
\hline \multicolumn{5}{|l|}{ Severity of Mental } \\
\hline Retardation & $3(7,5)$ & & & \\
\hline Mild & $3(1.5)$ & $5(12.5)$ & $2(5)$ & 0.61 \\
\hline Moderate & $4(10)$ & $15(37.5)$ & $1(2.5)$ & 1 \\
\hline \multicolumn{5}{|l|}{ Cause of Mental } \\
\hline \multicolumn{5}{|l|}{ Retardation } \\
\hline Prenatal Damage & $2(5)$ & $12(30)$ & $1(2.5)$ & \\
\hline Delivery Damage & $1(2.5)$ & $2(5)$ & $0(0)$ & 8.04 \\
\hline Postnatal Damage & $2(5)$ & $3(7.5)$ & $2(5)$ & 0.23 \\
\hline Other reasons & $2(5)$ & $13(32.5)$ & $0(0)$ & \\
\hline
\end{tabular}

*EMR: Educable mentally retarded; **Due to the frequency of zero, some columns have been merged 
of diagnosis for mental disabilities in children could change the role and self-concept of mothers (15). In this regard, supportive education could help parents to direct their negative emotions properly, which will ultimately lead to constructive interactions between parents and EMR children. As a result, they will be able to obtain the necessary guidance to cope with the special conditions of their children and express their emotions effectively (14).

The findings of the present study were indicative of a significant correlation between maternal self-concept and age of EMR children. In previous studies in this regard, age of EMR children has been reported to be significantly associated with the level of parental stress (16-18).

Moreover, level of self-concept was lower in mothers with EMR children and lower socioeconomic status. This finding was consistent with the results of previous studies in this regard $(17,18)$. In the current study, no significant correlation was observed between maternal self-concept and the age and education level of the mothers. This was in line with the results obtained by Khamis, who evaluated the level of psychological distress among the parents of children with mental retardation (17).

On the other hand, no significant correlation was observed between maternal age and self-concept in the present study, which could be due to the limited age range of the mothers in the current study. Furthermore, no significant relationship was found between the selfconcept of mothers and birth rank of EMR children. Nevertheless, it seems that mothers with a healthy first child could cope better with the mental retardation of their other children. In the present research, no significant differences were observed between the selfconcept of mothers, number of children and gender of the child. On the other hand, the results obtained by Ays were indicative of a significant correlation between the number of children and patterns of family adaptation (14). It seems that parents are more concerned about the health and educability rather than the number or gender of their child.

\section{Conclusion}

In conclusion, the findings of the present study indicated that mothers with EMR children had relatively desirable self-concept. Moreover, maternal self-concept had no significant relationship with factors such as maternal age, education level, employment status, number of children, gender of the child, mental disorder severity, birth rank, cause of the mental disability, and family history of mental retardation. However, self-concept of the mothers with EMR children was significantly correlated with the age of the child and family income status.

One of the limitations of the present study was the small sample size, which might have affected the results. Therefore, it is recommended that future studies in this regard be performed on larger sample sizes. Moreover, the descriptive nature of the current study might have reduced the power of analysis, and further analytical investigations may be required

\section{Conflicts of interest}

None declared.

\section{Author's contributions}

All the authors equally contributed to the study's conception and design, data analysis and drafting of the manuscript.

\section{Acknowledgments}

Hereby, we extend our gratitude to the Deputy of Research at Tehran University of Medical Sciences for the financial support of this study. We would also like to thank all the mothers and personnel of the special primary school of Aran \& Bidgol city for assisting us in this research project.

\section{References}

1. Jafari NR, Mohammadi AN, Barfe T. The comparison of educable and normal primary students' parents using mental health, self-esteem and psychological well-being structure in Yazd. J Commun Health Res 2013; 1(3):185-91.

2. Salari M, Kashaninia Z, Davachi A, Zoladl M, Babaei G. Effect of education on coping strategies of mothers who have educable mentally retarded children. Armaghane 
Danesh 2001; 6(23):1-9 (Persian).

3. Koohsali M, Mirzamani M, Mohammadkhani P, Karimlo M. Comparison of adjustment in mothers of educable mentally retard daughter. J Behav Sci 2008; 2(2):165-72 (Persian).

4. Kermanshahi M, Vanki S, Ahmadi F, Azadfalah P, Kazemnejhad A. Mother's experiences of having mental retard child. J Rehabil 2006; 7(26):26-33.

5. Kratochwill TR, Morris RJ. The practice of child therapy. $4^{\text {th }}$ ed. Mahwah, NJ: Erlbaum; 2007. p. 463-66.

6. Taghavi T, Aliakbarzade-Arani Z, Khari-Arani M. Adaptation in mothers of educable mentally retarded children. Nurs Midwifery Stud 2012; 1(1):41-4.

7. Collett JL. What kind of mother am I? Impression management and the social construction of motherhood. Symb Interact 2005; 28(3):327-47.

8. Krueger C, Trussoni K. Women's self-concept and the effects of positive or negative labeling behaviors'. UW-L J Undergrad Res 2005; 8:1-4.

9. Marriner-Tomey A, Alligood MR. Nursing theorists and their work. New York, USA: Mosby; 2006. P. 355-63.

10. Dehghannayeri N, Jalalinia F. Theorems and nursing theories. $1^{\text {st }}$ ed. Tehran: Boshra; 2004. P. 188-93 (Persian).

11. Taghavi Larijani T, Ghadirian F, Aliakbarzadeh Arani Z, Sharifi N, Noghani F, Faghihzadeh S. The effect of a psycho educational program for mothers of educable mentally retarded children: based on Roy's adaptation theory. Eur J Soc Bahav Sci 2012; 2(9):231-49.
12. Ford K, Hoyer P, Weglicki L, Kershaw T, Schram C, Jacobson M. Effects of a prenatal care intervention on the self-concept and self-efficacy of adolescent mothers. J Perinat Educ 2001; 10(2):15-22.

13. Craven RG, Marsh HW. The centrality of the self-concept construct for psychological wellbeing and unlocking human potential: implications for child and educational psychologists. Educat Child Psychol 2008; 25(2):104-18.

14. Ays H. Child-family characteristics and coping patterns of Indonesian families with a mentally retarded child. [Dissertation]. Washington, DC: Catholic University of American; 1993.

15. Moore LA. The lived experience of being a mother of a child with severe cerebral palsy. [Dissertation]. Ohio: Ohio medical college; 2005.

16. Emerson E. Mothers of children and adolescents with intellectual disability: social and economic situation, mental health status, and the self-assessed social and psychological impact of the child's difficulties. J Intellect Disabil Re 2003; 47(Pt 4-5):385-99.

17. Khamis V. Psychological distress among parents of children with mental retardation in the United Arab Emirates. Soc Sci Med 2007; 64(4):850-7.

18. Baker BL, Mcintyre LL, Blacher J, Crnic K, Edelbrock C, Low C. Pre-school children with and without developmental delay: behavior problems and parenting stress over time. J Intellect Disabil Res 2003; 47(Pt 4-5):217-30. 